\title{
Lower Primary School Students' Scientific Arguments
}

\author{
E. Taralli and M. Skoumios
}

\section{ABSTRACT}

\begin{abstract}
The present study investigates the structure and the content of oral scientific arguments constructed by the 6-year-old students in Greece when they answered questions about light propagation through objects, the dissolution of substances in water, and the flow of electric current through objects. The research was conducted with the participation of 64 primary school students (6 years old), while the interview served as the data collection tool. Research data included students' answers (arguments) to the questions of the interview. Students' scientific arguments were analyzed through rubrics evaluating the sufficiency and the appropriateness of the components of the arguments. The analysis of the data allowed the categories of students' arguments to be determined. It was found that students' arguments included sufficient and appropriate claims, some of them included sufficient and appropriate evidence, but they included no reasonings or rebuttals at all.
\end{abstract}

Keywords: Arguments, Primary School, Science Education

\author{
Published Online: February 18, 2022 \\ ISSN: $2736-4534$ \\ DOI :10.24018/ejedu.2022.3.1.244 \\ E. Taralli \\ Department of Primary Education, \\ University of the Aegean, Greece. \\ (e-mail: tarallievdokia ${ }^{\circledR}$ gmail.com) \\ M. Skoumios* \\ Department of Primary Education, \\ University of the Aegean, Greece. \\ (e-mail: skoumios ${ }^{\circledR}$ rhodes.aegean.gr) \\ *Corresponding Author
}

\section{INTRODUCTION}

The construction of scientific arguments by students has been recognized as a particularly important science practice, mainly in the last decade, and is at international level one of the main goals of science education (Driver et al., 2000; González-Howard \& McNeill, 2019; Henderson et al. 2018; NRC, 2012; OECD, 2013; Schwarz \& Baker, 2017). In particular, within the Framework for K-12 Science Education of the US National Research Council there is extensive reference to the need for students engaging in argument based on evidence (NRC, 2012).

However, although the construction of scientific arguments by the students is considered important, research investigating the quality of their scientific arguments is limited (Bravo-Torija \& Jiménez-Aleixandre, 2018; McNeill \& Krajcik, 2012). This research is mainly focused on secondary education students, while part of the research deals with upper primary school students (Choi \& Hand, 2020). Therefore, the necessity of conducting research investigating the quality of lower primary school students' scientific arguments emerges. Considering the above, the present study is focused on studying the structure and the content of oral scientific arguments of lower primary school students in Greece about light propagation through objects, the dissolution of substances in water, and the flow of electric current through objects. These domains constitute subjects of science curriculum for primary education.

\section{THEORETICAL FRAMEWORK}

\section{A. Science Education and Scientific Arguments}

In addition to knowledge, science also involves practice. "Science is not just a body of knowledge ... it is also a set of practices used to establish, extend, and refine that knowledge. Both elements - knowledge and practice - are essential" (NRC, 2012, p. 26). The term science practices describe the processes by which scientists engage as they study and construct models and theories about the natural world (NGSS Lead States, 2013). Students' understanding of the science ideas and concepts is based on their engagement with science practices (NRC, 2012). One of the science practices is to engage students in arguments. Through this practice, it is intended that the students be able to support their claims and assess others' arguments they are presented with (Duschl et al., 2007). It is deemed necessary that the students assess the available data in order to select sufficient and appropriate evidence and reasonings and develop scientific arguments.

It has been argued that constructing scientific arguments could help students understand science ideas and concepts (González-Howard \& McNeill, 2019). Moreover, research data has demonstrated that constructing arguments helped students understand the nature of scientific knowledge (Duschl, 2003; Leung, 2020; McDonald, 2010; Sandoval \& Reiser, 2004), construct new knowledge (Klein, 2004; Rivard \& Straw, 2000; Zohar \& Nemet, 2002) and may change or refine students' image of science (Bell \& Linn, 2000; Driver et al., 2000). 


\section{B. Students' Scientific Arguments: Components and Quality}

A scientific argument intends to support or refute a claim using reasons acceptable by the scientific community (Phillips \& Norris, 1999). Based on Toulmin's Argument Pattern (Toulmin, 1958), a modified and more simplified version has been proposed for students in the domain of science education (McNeill \& Krajcik, 2012). In particular, a scientific argument, according to McNeill and Krajcik (2012), consists of four components: claim, evidence, reasoning and rebuttal. The claim is an assertion or a conclusion answering a question. The evidence is the data supporting the claim, such as measurement or observation that is used to support the validity of the claim. The reasoning is a justification connecting the claim with the evidence and revealing the reason why data is considered evidence supporting the claim through appropriate scientific principles. The rebuttal justifies how or why an alternative claim is wrong (McNeill \& Krajcik, 2012).

The quality criteria of an argument are related to the structure and the content of the argument (McNeill et al., 2006; Sandoval \& Millwood, 2005). The structure of a scientific argument is related to the presence and the sufficiency of its components, regardless of their conceptual content (McNeill et al., 2006). The content of an argument is related to the appropriateness of its components when they are evaluated in relation to school knowledge (Sandoval \& Millwood, 2005).

\section{LITERATURE REVIEW}

Previous research has shown the difficulties that secondary or upper primary school students had in constructing scientific arguments. Students usually proposed claims without justifying them (Jiménez-Aleixandre et al., 2000, Sadler, 2004) or they proposed insufficient and inappropriate evidence (Bell \& Linn, 2000; Chinn \& Brewer, 2001; Choi et al., 2010; Heng et al., 2015; Jiménez-Aleixandre et al., 2000; McNeill \& Krajcik, 2012; Moje et al., 2004; Sadler, 2004; Sandoval \& Millwood, 2005). Also, students rarely used reasonings in the arguments they constructed (Chen et al., 2019; Hogan \& Maglienti, 2001; Konstantinidou \& Macagno, 2013; McNeill \& Krajcik, 2007, 2012; Moje et al., 2004; Sadler, 2004; Sampson et al., 2013; Songer \& Gotwals, 2012; Vuola \& Nousiainen, 2020). Moreover, their ability to construct rebuttals was limited (Chen et al., 2016; McNeill \& Krajcik, 2012; Sandoval \& Cam, 2011). Therefore, most students' quality of scientific arguments is low (RodríguezMora et al., 2021).

The above research involved students of secondary education or upper primary education. The research investigating the quality of preschool children and lower primary school students' scientific arguments is particularly limited (Choi et al., 2010; Convertini, 2021). Also, the types of scientific arguments produced by lower primary school students have not been studied. In addition, research that has been conducted so far has investigated the structure and the content of students' arguments as a whole rather than separately. There is no research separately evaluating the structure and the content of primary school students' scientific arguments. Therefore, the necessity of conducting research that focuses on the types of scientific arguments that lower primary school students construct and separately investigates the structure and the content of their arguments emerges.

\section{Aim AND RESEARCH QUESTIONS}

The present study investigates the types and the quality of oral scientific arguments constructed by 6-year-old primary school students in Greece after answering questions about the propagation of light through transparent and opaque objects, the dissolution of substances in water, and the flow of electric current through objects.

More specifically, the present study intended to answer the following research questions:

(a) What are the types of 6-year-old primary school students' scientific arguments?

(b) What is the level of the structure of 6-year-old primary school students' scientific arguments?

(c) What is the level of the content of 6-year-old primary school students' scientific arguments?

\section{METHOD}

\section{A. General Background and Participants}

A qualitative research approach for this study was used. In particular, the phenomenological method was used to understand how students make meaning of the phenomenon being studied. Phenomenology is effective in studying a small number of subjects to identify the core of their experiences with the phenomenon (Creswell, 2003). For this study, interviews were the method of data collection. Specifically, semi-structured interview approach was used to carry on conversations that would elicit rich data that could be used in qualitative analysis (Lofland, 1971). Semi-structured interviews give students more room to answer in terms of what is important to them (Strauss \& Corbin, 1998). This study conducted through personal semi-structured interviews in three stages.

The first stage included designing the questions of the interview in order to investigate the quality of students' scientific arguments. At first, the interview questions were given to two science education researchers, who made the necessary corrections. The questions were also presented to three students (pilot research) so that any ambiguous points could be detected. According to the remarks that were made, all modifications required were made and the final version of the interview questions was reached.

The second stage included students' interviews. At first, students' parents and primary school teachers were informed about the goals and the content of the research. The interviews were conducted following scheduled appointments with each and every student at a predetermined time and place. In case a student did not feel like answering, the interview would not take place. The interview of every student had an average duration of 30 minutes. The interviews were taped with the written consent of both students' parents and teachers. 
In the third stage, after data collection had been completed through the semi-structured interviews and the latter were transcribed, data analysis was conducted using rubrics separately evaluating the structure and the content of students' arguments. The rubrics were developed for the needs of the research (Tables I and II). After data analysis, the results and the conclusions of the research were drawn.

The research was conducted with the participation of 646 year-old students. The research sample included first-grade Greek primary school students selected at random in the academic year 2019-2020.

To ensure compliance with the ethical standards and research rules, approval was granted by the University's ethical committee. Before proceeding to interviews, we obtained permission from the school principal and the teachers of the classes. Furthermore, we provided beforehand, the students concerned as well as their parents with information about the aims, the content, the expected duration and the procedures of interview, and we obtained their consent.

\section{B. Instrument and Procedures}

The semi-structured interview was the tool for data collection in the present study. The interview intended to make the students produce oral scientific arguments about light propagation through objects, the dissolution of substances in water, and the flow of electric current through objects. The three interview questions were formed based on the framework for evaluating students' scientific arguments by Knight et al. (2013).

In the first question, the researcher conducting the interviews said to each student that two children of a school wanted to know whether light can propagate through all objects. Then he said that the children, because they disagreed with one another, took paperboard, a plastic transparency, a book and a glass and, while throwing light on them with a torch, they observed whether light propagates through them or not. In the room where the interview took place the researcher had put the torch, the paperboard, the transparency, the book and a glass on a table. He threw light on the objects and discussed with each student his/her observations about whether light can propagate through the objects. Then each and every student was asked to answer the question as to whether light propagates through all of the objects or through only some of them and not through the others. The students were recommended not to forget to state why they thought their answer was correct and why every other answer was wrong. The Appendix includes the first question of the interviews.

Regarding the second question, the researcher said to every student that the two children wanted to know whether all substances are dissolved in water. Following a similar procedure as in the previous question, the researcher poured different substances into the water and discussed with every student his/her remarks about whether the substance is dissolved in the water. Both water-soluble and insoluble substances were used. Then every student was asked to answer the question asking whether all substances are dissolved in water or only some of them while others are not.

There was also a third question asking whether electric current can flow through all objects. The researcher constructed an open electrical circuit using a battery, wires and a little lamp, and then put an object between the free cable ends and discussed with every student his/her observations as to whether the electric current flows through the object. The objects included both conductors and insulators. Next, every student was asked to answer whether the electric current flows through all the objects or only through some of them and does not flow through others. In both last two questions, the students also were recommended not to forget to state why they thought their answer was correct and why every other answer was wrong.

Data research included students' oral scientific arguments in the three above questions. A total of 192 arguments were collected ( 64 about light propagation, 64 about the dissolution of substances in water, and 64 about the flow of electric current).

\section{Data Analysis}

McNeill and Krajcik (2007) proposed a rubric for assessing the quality of students' scientific arguments. Through this rubric the components of an argument can be classified into levels. This rubric assesses in a uniform way both the structure and the content of the arguments. Therefore, through this framework, it is not possible to evaluate the structure of students' written arguments separately from the evaluation of their content. It is also necessary to note that the above framework for assessing the quality of an argument lacks the element of rebuttal. It follows, it is necessary to establish a framework that includes - in addition to claim, evidence and reasoning - also rebuttals and that distinctly assesses the structure and content of students' arguments. Therefore, two different frameworks of analysis were developed (Tables I and II). More specifically, in the present study, students' scientific arguments were separately assessed in relation to their structure and content using two rubrics assessing the structure (sufficiency of components) and the content (appropriateness of components) of arguments, respectively. Arguments were assessed in relation to all their four components (claim, evidence, reasoning, rebuttal) for both structure and content.

Table I presents the rubric used for assessing the structure of arguments. In particular, the rubric assesses the presence and sufficiency of argument components regardless of their conceptual content.

TABLE I: RUBRIC ASSESSING THE STRUCTURE OF STUDENTS' SCIENTIFIC

\begin{tabular}{ccc}
\hline & ARGUMENTS & \\
\hline \hline $\begin{array}{c}\text { Scientific argument } \\
\text { components }\end{array}$ & Level 0 & Level 1 \\
\hline Claim & Does not suggest a & claim \\
& Does not suggest & Suggests a claim \\
Evidence & evidence or suggests & sufficient \\
& insufficient evidence & evidence \\
& Does not suggest & Suggests \\
Reasoning & reasoning or suggests & sufficient \\
& insufficient reasoning & reasoning \\
& Does not suggest a & Suggests a \\
& rebuttal or suggests an & sufficient \\
Rebuttal & insufficient rebuttal & rebuttal \\
& &
\end{tabular}


Table II presents the rubric used for assessing the content of arguments. In particular, the rubric assesses the appropriateness of argument components (whether they are in agreement with school knowledge) regardless of their sufficiency.

Before data analysis, pilot analysis was performed on some of the arguments. Pilot research was necessary to ensure the validity of the frameworks of analysis. Students' arguments were evaluated by two independently working researchers, who settled their disagreements through discussion. After students' arguments were analyzed, the types of the arguments as well as the frequencies of sufficiency and appropriateness levels of their components of students' arguments were identified.

TABLE II: RUBRIC ASSESSING THE CONTENT OF STUDENTS' SCIENTIFIC

\begin{tabular}{|c|c|c|}
\hline \multicolumn{3}{|c|}{ ARGUMENTS } \\
\hline $\begin{array}{l}\text { Scientific argument } \\
\text { components }\end{array}$ & Level 0 & Level 1 \\
\hline Claim & $\begin{array}{l}\text { Does not suggest a } \\
\text { claim or suggests an } \\
\text { inappropriate claim }\end{array}$ & $\begin{array}{c}\text { Suggests an } \\
\text { appropriate claim }\end{array}$ \\
\hline Evidence & $\begin{array}{l}\text { Does not suggest } \\
\text { evidence or suggests } \\
\text { inappropriate evidence } \\
\text { (may include } \\
\text { some appropriate } \\
\text { evidence) }\end{array}$ & $\begin{array}{l}\text { Suggests } \\
\text { appropriate } \\
\text { evidence }\end{array}$ \\
\hline Reasoning & $\begin{array}{l}\text { Does not suggest } \\
\text { reasoning or suggests } \\
\text { inappropriate } \\
\text { reasoning }\end{array}$ & $\begin{array}{l}\text { Suggests } \\
\text { appropriate } \\
\text { reasoning }\end{array}$ \\
\hline Rebuttal & $\begin{array}{l}\text { Does not suggest a } \\
\text { rebuttal or suggests an } \\
\text { inappropriate rebuttal }\end{array}$ & $\begin{array}{l}\text { Suggests an } \\
\text { appropriate } \\
\text { rebuttal }\end{array}$ \\
\hline
\end{tabular}

\section{RESULTS}

\section{A. Scientific Argument Types}

Arguments Including Sufficient and Appropriate Claims and Evidence, without any Reasonings or Rebuttals (Type 1): Data analysis showed that most students' arguments included sufficient and appropriate claims supported by sufficient and appropriate evidence, but they did not include any reasonings or rebuttals at all (72 out of 192 arguments). For example, a student put forward the following argument: "Light passes through some objects but does not pass through others. Light passes through the glass but does not pass through the book." Regarding its structure, this argument includes a claim ("Light passes through some objects but does not pass through others") and evidence ("Light passes through the glass but does not pass through the book"). More specifically, it includes a claim considered sufficient (Level 1) and evidence considered sufficient (Level 1), but it does not include a reasoning (Level 0) or a rebuttal (Level 0). As for its content, this argument includes a claim considered appropriate (Level 1) and appropriate evidence (Level 1), but it does not include a reasoning (Level 0) or a rebuttal (Level $0)$.
Arguments with Sufficient and Appropriate Claims, Insufficient and Inappropriate Evidence, without Reasonings or Rebuttals (Type 2): These students' arguments include sufficient and appropriate claims supported by insufficient and inappropriate evidence, while no reasonings or rebuttals were included in them (36 out of 192 arguments). The following argument is a typical example: "Light does not pass through some objects but it passes through others. Light does not pass through thick objects." Concerning its structure, this argument includes a claim ("Light does not pass through some objects but it passes through others") and evidence ("Light does not pass through thick objects"). In particular, it includes a claim considered sufficient (Level 1) and evidence considered insufficient (Level 0), but it does not include a reasoning (Level 0) or a rebuttal (Level 0). As for its content, this argument includes a claim considered appropriate (Level 1) and inappropriate evidence (Level 0), but it does not include a reasoning (Level 0) or a rebuttal (Level 0).

Arguments with Sufficient and Appropriate Claims, Insufficient and Appropriate Evidence, without Reasonings or Rebuttals (Type 3): This type contains some students' arguments that included sufficient and appropriate claims supported by insufficient and appropriate evidence, but they did not include any reasonings or rebuttals (24 out of 192 arguments). For example, a student put forward the following argument: "Light passes through some objects but does not pass through others. Light does not pass through the book." Regarding its structure, this argument includes a claim ("Light passes through some objects but does not pass through others") and evidence ("Light does not pass through the book"). More specifically, it includes a claim considered sufficient (Level 1) and evidence considered insufficient (Level 0), but it does not include a reasoning (Level 0) or a rebuttal (Level 0). As for its content, this argument includes a claim considered sufficient (Level 1) and appropriate evidence (Level 1), but it does not include a reasoning (Level 0) or a rebuttal (Level 0).

Arguments with Sufficient and Appropriate Claims, without Evidence, Reasonings or Rebuttals (Type 4): These students' arguments included only sufficient and appropriate claims not supported by evidence. In addition, they did not include any reasonings or rebuttals (24 out of 192 arguments). For example, a student provided the following answer to the question it was asked: "Light does not pass through all objects. It passes through some objects, but it does not pass through others." Regarding its structure this argument includes only a claim ("Light does not pass through all objects. It passes through some objects, but it does not pass through others."). In particular, it includes a claim considered sufficient (Level 1), but it does not include any evidence (Level 0) or reasonings (Level 0) or rebuttals (Level 0). As for its content, this argument includes a claim considered sufficient (Level 1), but it does not include any evidence (Level 0), reasonings (Level 0) or rebuttals (Level 0).

Arguments with Sufficient and Inappropriate Claims without Evidence, Reasonings or Rebuttals (Type 5): This type includes arguments that (apart from not including evidence, reasonings or rebuttals) included only inappropriate claims (36 out of 192 arguments). 


\section{B. Structure of Scientific Arguments}

Fig. 1. shows the distribution of sufficiency levels of claims, evidence, reasonings and rebuttals of students' arguments.

It is inferred that most arguments included sufficient claims, while only few of them did not include any claims at all. As for the presence and sufficiency of evidence included in students' arguments, although most of them did not include any evidence or included insufficient evidence, there were several arguments including sufficient evidence. Furthermore, students' arguments did not include any reasonings or rebuttals.

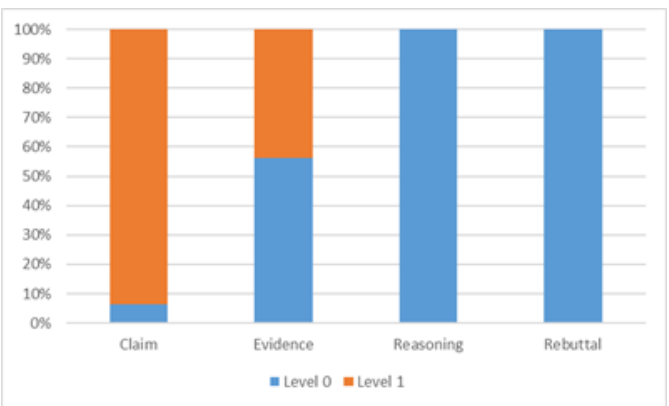

Fig. 1. Percentages of sufficiency levels of claims, evidence, reasonings and rebuttals in students' arguments.

\section{Content of Scientific Arguments}

Fig. 2. depicts the distribution of content levels of claims, evidence, reasonings and rebuttals in students' arguments.

It is inferred that most arguments included appropriate claims, while only few of them included partially appropriate claims or inappropriate claims. Regarding the appropriateness of the evidence included in students' arguments, half of them did not include any evidence or included inappropriate evidence, while the other half included appropriate evidence. Furthermore, students' arguments did not include appropriate reasonings and rebuttals.

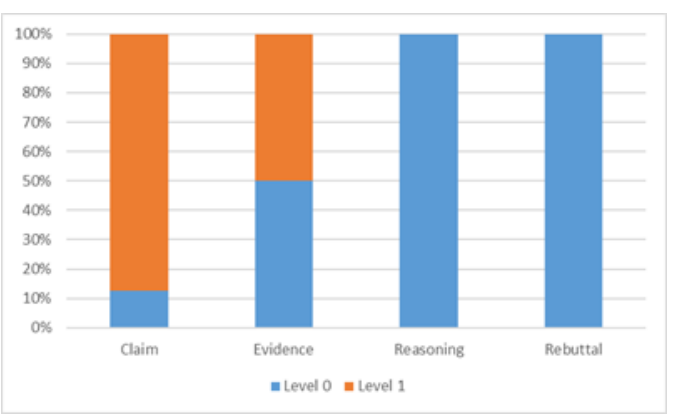

Fig. 2. Percentages of appropriateness levels of claims, evidence, reasonings and rebuttals in students' arguments.

\section{DISCUSSION}

The results of the present paper demonstrated that most primary school students' scientific arguments were described by sufficient and appropriate claims. As for the sufficiency of evidence, it was found that almost half of the arguments included sufficient evidence, while the other half either did not include any evidence or the evidence they included was insufficient. As for the appropriateness of evidence, it was found that half of the arguments included appropriate evidence, while the other half included inappropriate evidence. Furthermore, none of the arguments included any reasonings or rebuttals.

The quality of the scientific arguments constructed by lower primary school students when they answered to questions is comparable to the quality of older students' arguments. As a matter of fact, the above results are in agreement with the results of other studies on secondary education students or even on higher primary school students, which showed that the quality of scientific arguments constructed by students of different ages was low. To be more specific, it was found that in the scientific arguments they constructed, the students usually proposed claims without evidence, reasonings or rebuttals (Jiménez-Aleixandre et al., 2000; Sadler, 2004). Furthermore, it was found that in case the students proposed scientific arguments including evidence, the latter was usually insufficient or inappropriate (Bell \& Linn, 2000; Chinn \& Brewer, 2001; Choi et al., 2010; Heng et al., 2015; Jiménez-Aleixandre et al., 2000; McNeill \& Berland, 2017; McNeill \& Krajcik, 2012; Moje et al., 2004; Sadler, 2004; Sandoval \& Millwood, 2005). In addition, those studies also showed that students rarely included reasonings (McNeill \& Krajcik, 2007, 2012; Moje et al., 2004; Sadler, 2004; Sampson et al., 2013; Songer \& Gotwals, 2012) or rebuttals (McNeill \& Krajcik, 2012) in the scientific arguments they constructed.

The finding that most students' scientific arguments, in both primary and secondary education, were of low quality could be attributed to the fact that in science teaching the students are rarely taught the structure of a scientific argument and do not become familiar with procedures for constructing scientific arguments (Cherbow et al., 2021; Driver et al., 2000). Also, no opportunities are provided to the students through the content of school textbooks so that they construct arguments (Papakonstantinou \& Skoumios, 2021). Furthermore, rarely are the students asked in science teaching to assess (in relation to structure and content) their or others' scientific arguments (Driver et al., 2000; Knight et al., 2014; Leung, 2020).

It should be stressed that the results of the present study are subject to the restrictions of the small sample, which cannot be considered representative of the entire population of students. An additional restriction to this study is the use of only three questions for data collection.

It has been underlined that the creation of a framework of analysis helping both teachers and students in the procedure for supporting a claim is necessary (Convertini, 2021; Henderson et al., 2018; McNeill \& Krajcik, 2012; McNeill et al., 2018). The framework proposed for assessing the structure and the content of lower primary school students' arguments (see Tables I and II) could contribute to this direction. More specifically, it could be used in the fields of science teaching practice and research. In the field of science teaching practice, this tool could be used by the teachers for systematically assessing their students' scientific arguments. Also, the use of this framework could help the teacher study the development of the structure and the content of a student's arguments over the course of time. In the field of research, this framework could contribute to assessing the structure and the content of students' scientific arguments during the 
instruction aiming to develop students' ability to construct scientific arguments.

\section{CONCLUSIONS}

Regarding both structure and content most of lower primary school students constructed low level scientific arguments. The arguments included claims and some of them even evidence. However, neither reasonings nor rebuttals were included in the arguments.

Therefore, it becomes evident that there is necessity of proposing teaching strategies that can be used by the teachers in order to support the students so that the latter can construct scientific arguments and mainly include evidence, reasonings and rebuttals in them. More specifically, it has been suggested that before asking from the students to construct a scientific argument, teachers should explain to the students what a scientific argument is and what its components are (Çetin, 2014; Lizotte, et al., 2004; McNeill \& Krajcik, 2008). The teachers can then discuss with the students and explain to them each and every component of a scientific argument. They are even recommended to at first process with their students the first two components of an argument (claim, evidence) and, after the students have become familiar with them, the teachers can introduce the reasoning and then the rebuttal (Songer et al., 2009).

Apart from explicit teaching to the structure of a scientific argument, the teachers are recommended to present examples of scientific arguments to their students and discuss with them the quality of these arguments (McNeill \& Krajcik, 2008). The teachers can help students to identify the strong and weak points of the scientific arguments, focusing on the sufficiency and appropriateness of their components. These actions can help students understand how to construct scientific arguments and how to critique the quality of arguments (Krajcik \& McNeill, 2009; Mastrogiorgaki \& Skoumios, 2018; McNeill \& Krajcik, 2008).

The students can be helped in constructing scientific arguments when the teachers provide them with supporting frameworks that can be used for constructing arguments or reformulating their arguments. The teachers are recommended to provide the students with opportunities to evaluate by themselves the arguments they construct (selfevaluation) (McNeill \& Krajcik, 2008). The teachers can support the students by providing them with frameworks of analysis or rubrics so that the students can use them in order to evaluate their scientific arguments. Also, the teachers are recommended to engage the students with activities providing supporting "language frameworks" that could be used by the students in order to construct arguments (Mercer et al., 2004). Relatively recent research attempts with encouraging results is focused on this direction of implementing the above teaching strategies followed mainly in secondary education (Berland \& Reiser, 2009; Choi et al., 2010; GonzálezHoward et al., 2019; Leung, 2020; Mastrogiorgaki \& Skoumios, 2018; McNeill \& Krajcik, 2012; Sampson et al., 2011; Smprinis \& Skoumios, 2021).

The present paper contributes to the research on studying students' scientific arguments because its findings shed light on this research field by separately studying the structure and the content of lower primary school students' arguments, an issue with no previous empirical data at all. However, further research is required for both studying the quality (structure and content) of students' arguments in other science issues (apart from the propagation of light, the dissolution of substances in water, and the flow of electric current) and for comparing the results of this new research with the results of the present research.

In addition, this paper was focused on studying the quality of scientific arguments constructed by the students. It would be of research interest to investigate students' abilities to not only construct scientific arguments but also critique scientific arguments they study. Also, the development of teaching interventions aiming at developing lower primary school students' abilities to construct scientific arguments (through teaching strategies), their implementation in students, and the assessment of their learning outcomes relating to the development of the quality (structure and content) of students' arguments are also recommended.

\section{APPENDIX}

The first question of the interview.

Yiannis, Kostas and Panagiota want to know whether light can pass through all objects. They used a piece of cardboard, a transparency, a book and a glass and threw light on them with a torch.

A. They threw light on a piece of cardboard.

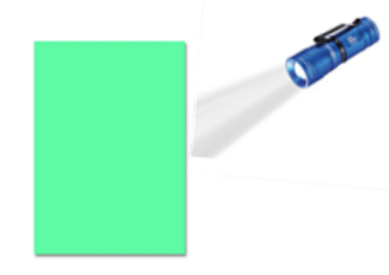

They observed that light does not pass through the cardboard.

B. They threw light on a transparency.

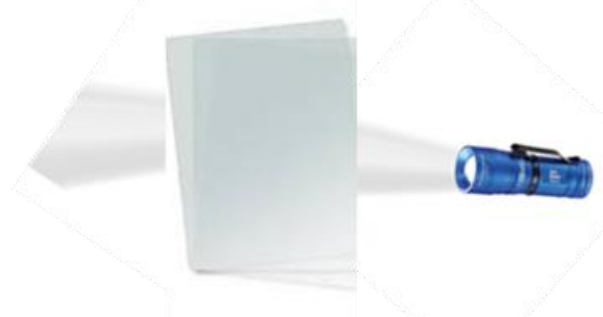

They observed that light passes through the transparency. C. They threw light on a book.

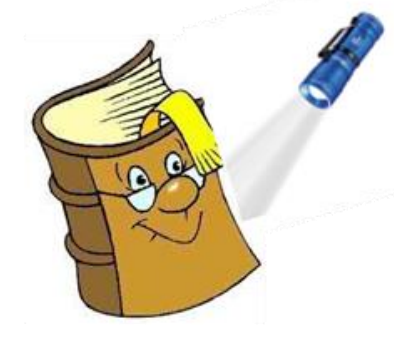

They observed that light does not pass through the book. D. They threw light on a glass. 


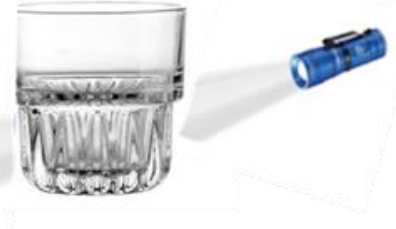

They observed that light passes through the glass.

The children need your help. They have different ideas. Panagiota says that light does not pass through all objects. On the other hand, Kostas says that light passes through all objects.

Use the information provided above in order to answer the following question:

Does light pass through all objects or it passes only through some of them while it does not pass through others?

Do not forget to state why you think your answer is correct and why every other answer is wrong.

\section{CONFLICT OF INTEREST}

Authors declare that they do not have any conflict of interest.

\section{REFERENCES}

Bell, P., \& Linn, M.C. (2000). Scientific arguments as learning artifacts: Designing for learning from the Web with KIE. International Journal of Science $\quad$ Education, 22(8), 797-817. https://doi.org/10.1080/095006900412284

Berland, L. K., \& Reiser, B. J. (2009). Making sense of argumentation and explanation. Science Education, 93, 26-55. https://doi.org/10.1002/sce.20286

Bravo-Torija, B., Jiménez-Aleixandre, MP. (2018). Developing an Initial Learning Progression for the Use of Evidence in Decision-Making Contexts. International Journal of Science and Mathematics Education, 16, 619-638. https://doi.org/10.1007/s10763-017-9803-9

Çetin, P. S. (2014). Explicit argumentation instruction to facilitate conceptual understanding and argumentation skills. Research in Science \& Technological Education, 32(1), 1-20. https://doi.org/10.1080/02635143.2013.850071

Chen, H.T., Wang, H.H., Lu, Y.Y., Lin, H., \& Hong, Z.R. (2016). Using a modified argument-driven inquiry to promote elementary school students' engagement in learning science and argumentation. International Journal of Science Education, 38(2), 170-191. https://doi.org/10.1080/09500693.2015.1134849

Chen, H.T., Wang, H.H., Lu, Y.Y. \& Hong, Z.R. (2019). Bridging the Gender Gap of Children's Engagement in Learning Science and Argumentation Through a Modified Argument-Driven Inquiry. International Journal of Science and Mathematics Education, 17, 635655. https://doi.org/10.1007/s10763-018-9896-9

Cherbow, K., Lowell, B. R., \& McNeill, K. L. (2021). Redesign or relabel? How a commercial curriculum and its implementation oversimplify key features of the NGSS. Science Education, 105(1), 5-32. https://doi.org/10.1002/sce. 21604

Chinn, C. A. \& Brewer, W. F. (2001). Models of data: A theory of how people evaluate data. Cognition and Instruction, 19(3), 323-393. https://doi.org/10.1207/S1532690XCI1903_3

Choi, A., \& Hand, B. (2020). Students' Construct and Critique of Claims and Evidence Through Online Asynchronous Discussion Combined with In-Class Discussion. International Journal of Science and Mathematics https://doi.org/10.1007/s10763-019-10005-4

Choi, A., Notebaert, A., Diaz, J., \& Hand, B. (2010). Examining arguments generated by year 5,7 , and 10 students in science classrooms. Research in Science Education, 40, 149-169. https://doi.org/10.1007/s11165008-9105-x

Convertini, J. (2021). An Interdisciplinary Approach to Investigate Preschool children's Implicit Inferential Reasoning in Scientific Activities. Research in Science Education, 51, 171-186. https://doi.org/10.1007/s11165-020-09957-3
Creswell, J. W. (2003). Research design: Qualitative, quantitative, and mixed methods approaches (2nd ed.). Thousand Oaks, CA: Sage Publications, Inc.

Driver, R., Newton, D., \& Osborne, J. (2000). Establishing the norms of scientific argumentation in classrooms. Science Education, 84(3), 287312 . 237X(200005)84:3<287::AID-SCE1>3.0.CO;2-A

Duschl, R. A. (2003). Assessment of inquiry. In J. M. Atkin \& J. E. Coffey (Eds.) Everyday assessment in the science classroom (pp. 41-59). National Science Teachers Association Press.

Duschl, R.A., Schweingruber, H.A., \& Shouse, A.W. (2007). Taking Science to School: Learning and Teaching Science in Grades K-8. National Academies Press.

González-Howard, M., \& McNeill, K.L. (2019). Supporting linguistically diverse students in scientific argumentation across writing and talking. In Spycher, P. \& Haynes, E. (Eds.). Culturally and linguistically diverse learners and STEAM: Teachers and researchers working in partnership to build a better path forward (pp. 77-94). Information Age Publishing.

Henderson, J. B., McNeill, K. L., González-Howard, M., Close, K. \& Evans. M. (2018). Key Challenges and Future Directions for Educational Research on Scientific Argumentation. Journal of Research in Science Teaching, 55(1), 5-18. https://doi.org/10.1002/tea.21412

Heng, L. L., Surif, J., \& Seng, C. H. (2015). Malaysian students' scientific argumentation: Do groups perform better than individuals? International Journal of Science Education, 37(3), 505-528. https://doi.org/10.1080/09500693.2014.995147

Hogan, K., \& Maglienti, M. (2001). Comparing the epistemological underpinning of students' and scientists' reasoning about conclusions. Journal of Research in Science Teaching, 38(6), 663-687. https://doi.org/10.1002/tea.1025

Jiménez-Aleixandre, M.P., Bugallo Rodríguez, A., \& Duschl, R.A. (2000). Doing the lesson or doing science: Argument in high school genetics. Science Education, 84(6), 757-792. https://doi.org/10.1002/1098237X(200011)84:6<757::AID-SCE5>3.0.CO;2-F

Klein, G. (2004). The power of intuition. New York: A Currency Book/Doubleday.

Knight, A., McNeill, K. \& Pearson, P. D. (2014, April). Students' Abilities to Critique Scientific Arguments Based on the Form of Justification. Paper presented at the annual meeting of NARST, Pittsburg, PA.

Knight, A. M., McNeill, K. L., Corrigan, S., \& Barber, J. (2013, April). Student assessments for reading and writing scientific arguments. Paper presented at the annual meeting of the American Educational Research Association, San Francisco.

Konstantinidou, A., \& Macagno, F. (2013). Understanding students' reasoning: Argumentation schemes as an interpretation method in science education. Science \& Education, 22(5), 1069-1087. https://doi.org/10.1007/s11191-012-9564-3

Krajcik, J., \& McNeill, K. (2009). Designing Instructional Materials to Support Students' in Writing Scientific Explanations: Using Evidence and Reasoning Across the Middle School Years. Paper Presented at the annual meeting of the National Association for Research in Science Teaching, Hyatt Regency Orange County, Garden Grove, CA.

Leung, J.S.C. (2020). Students' adherences to epistemic understanding in evaluating scientific claims. Science Education, 104(2), 164-192. https://doi.org/10.1002/sce.21563

Lizotte, D. J., McNeill, K. L., \& Krajcik, J. (2004). Teacher Practices that Support Students' Construction of Scientific Explanations in Middle School Classrooms. In Kafai, Y. B., Sandoval, W. A., Enyedy, N., Nixon, A. S., \& Herrera, F. (Eds.), International Conference of the Learning Sciences 2004: Embracing Diversity in the Learning Sciences (pp. 310-317). Lawrence Erlbaum Associates.

Lofland, J. (1971). Analyzing social settings. Belmont, CA: Wadsworth.

Mastrogiorgaki, M. \& Skoumios, M. (2018). Improving the Structure of Students' Arguments Through a Teaching-Learning Sequence on Newton's Second Law. European Journal of Education Studies, 5(5), 1-10. http://dx.doi.org/10.46827/ejes.v0i0.2021

McDonald, C. V. (2010). The influence of explicit nature of science and argumentation instruction on preservice primary teachers' views of nature of science. Journal of Research in Science Teaching, 47(9), 1137-1164. https://doi.org/10.1002/tea.20377

McNeill, K. L. \& Berland, L. (2017). What is (or should be) scientific evidence use in K-12 classrooms? Journal of Research in Science Teaching. 54(5), 672-289. https://doi.org/10.1002/tea.21381

McNeill, K. L., \& Krajcik, J. (2007). Middle school students' use of appropriate and inappropriate evidence in writing scientific explanations. In M. C. Lovett \& P. Shah (Eds.), Carnegie Mellon symposia on cognition. Thinking with data (pp. 233-265). Lawrence Erlbaum Associates Publishers. 
McNeill, K. L. \& Krajcik, J. (2008). Scientific explanations: Characterizing and evaluating the effects of teachers' instructional practices on student learning. Journal of Research in Science Teaching, 45(1), 53-78. https://doi.org/10.1002/tea.20201

McNeill, K. L. \& Krajcik, J. (2012). Supporting grade 5-8 students in constructing explanations in science: The claim, evidence and reasoning framework for talk and writing. Pearson Allyn \& Bacon.

McNeill, K.L., Lizotte, D.J., Krajcik, J., \& Marx, R.W. (2006). Supporting students' construction of scientific explanations by fading scaffolds in instructional materials. Journal of the Learning Sciences, 15(2), 153191. https://doi.org/10.1207/s15327809j1s1502 1

McNeill, K. L., Marco-Bujosa, L. M., González-Howard, M., \& Loper, S. (2018). Teachers' enactments of curriculum: Fidelity to procedure versus fidelity to goal for scientific argumentation. International Journal of Science Education, 40(12), 1455-1475. https://doi.org/10.1080/09500693.2018.1482508

Mercer, N., Dawes, L., Wegerif, R., \& Sams, C. (2004). Reasoning as a scientist: Ways of helping children to use language to learn science. British Educational Research Journal,30(3), 359-377. https://doi.org/10.1080/01411920410001689689

Moje, E. B., Peek-Brown, D., Sutherland, L. M., Marx, R. W., Blumenfeld, P., \& Krajcik, J. (2004). Explaining explanations: Developing scientific literacy in middle-school project-based science reforms. In D Strickland \& D. E. Alvermann (Eds.), Bridging the gap: improving literacy learning for preadolescent and adolescent learners in grades (pp. 4-12). Carnegie Corporation.

National Research Council. [NRC] (2012). A framework for $K-12$ science education: Practices, crosscutting concepts, and core ideas. The National Academies Press.

NGSS Lead States. (2013). Next Generation Science Standards: For States, By States. The National Academies Press.

Organisation for Economic Co-operation and Development [OECD]. (2013). OECD skills outlook 2013: First results from the survey of adult skills. OECD Publishing.

Papakonstantinou, M., \& Skoumios, M. (2021). Science and engineering practices in the content of Greek middle school physics textbooks about forces and motion. Journal of Technology and Science Education, 11(2), 457-473. https://doi.org/10.3926/jotse.1286

Phillips, L. M., \& Norris, S. P. (1999). Interpreting popular reports of science: What happens when the reader's world meets the world on paper? International Journal of Science Education, 21, 317-327. https://doi.org/10.1080/095006999290723

Rivard, L. P., \& Straw, S. B. (2000). The Effect of Talk and Writing on Learning Science: An Exploratory Study. Science Education, 84, 566593. https://doi.org/10.1002/1098-237X(200009)84:5<566::AID$\mathrm{SCE} 2>3.0 . \mathrm{CO} ; 2-\mathrm{U}$

Rodríguez-Mora, F., D. Cebrián-Robles, \& Blanco-López, Á. (2021). An Assessment Using Rubrics and the Rasch Model of 14/15-Year-Old Students' Difficulties in Arguing about Bottled Water Consumption. Research in Science Education. https://doi.org/10.1007/s11165-020-09985-Z

Sampson, V., Grooms, J. \& Walker, J.P. (2011). Argument-Driven Inquiry as a way to help students learn how to participate in scientific argumentation and craft written arguments: An exploratory study. Science $\quad$ Education, $\quad 95(2), \quad 217-257$. https://doi.org/10.1002/sce.20421

Sampson, V., Enderle, P., Grooms, J., \& Witte, S. (2013). Writing to learn by learning to write during the school science laboratory: Helping middle and high school students develop argumentative writing skills as they learn core ideas. Science Education, 97(5), 643-670. https://doi.org/10.1002/sce.21069

Sadler, T. D. (2004). Informal reasoning regarding socioscientific issues: A critical review of research. Journal of Research in Science Teaching, 41(5), 513-536. https://doi.org/10.1002/tea.20009

Sandoval, W. A., \& Cam, A. (2011). Elementary children's judgments of the epistemic status of sources of justification. Science Education, 95(3), 383-408. https://doi.org/10.1002/sce.20426

Sandoval, W. A., \& Millwood, K. A. (2005). The quality of students' use of evidence in written scientific explanations. Cognition and Instruction, 23(1), 23-55. https://doi.org/10.1207/s1532690xci2301_2

Sandoval, W. A., \& Reiser, B. J. (2004). Explanation-driven inquiry: Integrating conceptual and epistemic scaffolds for scientific inquiry. Science Education, 88(3), 345-372. https://doi.org/10.1002/sce.10130

Schwarz, B. \& Baker, M. (2017). Dialogue, argumentation and education: History, theory and practice. Cambridge University Press.

Smprinis, A., \& Skoumios, M. (2021). Developing the structure of junior high school students' arguments about Ohm's law. Interdisciplinary Journal of Environmental and Science Education, 17(4), e2256. https://doi.org/10.21601/ijese/11137
Songer, N. B., \& Gotwals, A. W. (2012). Guiding explanation construction by children at the entry points of learning progressions. Journal of Research in Science Teaching, 49(2), 141-165. https://doi.org/10.1002/tea.20454

Songer, N. B., Kelcey, B., \& Gotwals, A. W. (2009). How and when does complex reasoning occur? Empirically driven development of a learning progression focused on complex reasoning about biodiversity. Journal of Research in Science Teaching, 46(6), 610-631. https://doi.org/10.1002/tea.20313

Strauss, A. M. \& Corbin, J. (1998). Basics of Qualitative Research: Techniques and Procedures for Developing Grounded Theory (3rd Edition.). Newbury Park, CA: Sage Publications, Inc.

Toulmin, S. (1958). The Uses of Argument. Cambridge University Press.

Vuola, K. \& Nousiainen, M. (2020). Physics knowledge justification: an analysis framework to examine physics content knowledge. Nordic Studies in Science Education, 16(2), 149-166. https://doi.org/10.5617/nordina.6916

Zohar, A., \& Nemet, F. (2002). Fostering students' knowledge and argumentation skills through dilemmas in human genetics. Journal of Research in Science Teaching, 39(1), 35-62. https://doi.org/10.1002/tea.10008

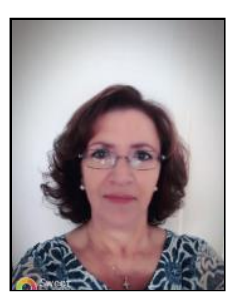

Evdokia Taralli is a Primary Education teacher born in Rhodes Island, Greece. She holds a bachelor's degree from the Department of Primary Education of the University of the Aegean. Also, she holds a master's degree in Environmental Education from the Department of Sciences Preschool Education and Educational Design, University of the Aegean. She is involved in work with research and development of science education at the Department of Primary Education of the University of the Aegean.

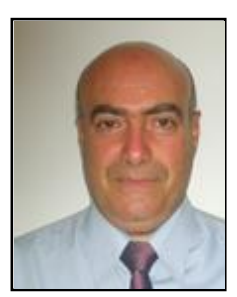

Michael Skoumios is Associate Professor of Science Education at University of the Aegean in Greece (Department of Primary Education). He obtained a first degree in Physics from the National and Kapodistrian University of Athens, a second degree in Education from the University of Aegean and his $\mathrm{PhD}$ in Science Education from the Hellenic Open University. His research interests include science concept learning and teaching science in primary and secondary schools as well as the analysis and development of educational materials. He has published a considerable number of research papers in journals, books and conference proceedings. $\mathrm{He}$ has also organized three conferences on Science and Mathematics Educational Materials. 